\title{
Study of Three Valves Command Laws of The Expansion Cylinder of a Hot Air Engine
}

\author{
Max Ndamé Ngangué ${ }^{1}$ Olivier Sosso Mayi² ${ }^{2}$ Pascal Stouffs ${ }^{1 *}$ \\ ${ }^{1}$ Univ. Pau \& Pays Adour/E2S UPPA, Laboratoire de Thermique, Energétique et Procédés-IPRA, \\ EA1932, F-64000 Pau, France \\ ${ }^{2}$ Department of Electrical Engineering, ENSET of Douala University, Cameroon, BP 1872 Douala, Cameroon \\ pascal.stouffs@univ-pau.fr
}

Received 19 December 2018, Revised 01 May 2019, Accepted 02 May 2019

\begin{abstract}
The family of hot air engines with external heat input is divided in two subgroups: the Stirling engines, invented in 1816, have no valves whereas Ericsson engines, invented in 1833, have valves in order to isolate the cylinders. The valves give some advantages to the Ericsson engine. Amongst them, the most important one is that the heat exchangers are not to be considered as unswept dead volumes whereas the Stirling engine designer is faced to the difficult compromise between heat exchanger transfer area maximization and heat exchanger volume minimization.

However, the distribution system of the Ericsson engine introduces some complexity and a non-negligible mechanical energy consumption in order to actuate them.

An original and very simple system called "bash-valve" is proposed to provide answers to the difficulties related to the distribution system of the Ericsson engine. The "bash-valve" technology has been used in steam piston engines and pneumatic piston engines. In this system, the piston itself actuates the opening of the valves when being around the top dead center. When its moves to the bottom dead center, the piston loses contact with the valves and it closes under the effect of the return spring. Three different valves command laws of the expansion cylinder of the proposed hot air engine are studied. A comparison between energy performance of the engine with the expansion cylinder equipped with two kinds of bash valve technology and the energy performance of the expansion cylinder of an incomplete expansion Joule Ericsson cycle engine is presented as well as their influence on the design of the system.
\end{abstract}

Keywords: Valves command laws; bash-valve; Ericsson engine; hot air engine; Joule cycle.

\section{Introduction}

The world is going through an energy crisis due to a massive population growth, the economic rise of emerging countries, the depletion of fossil fuel reserves, and the proliferation of conflicts in parts of the world because of the interest of some powerful countries in fossil fuels. Yet according to the International Energy Agency (IEA) in its 2014 report [1], fossil fuels account for just over $81 \%$ of the energy consumed in the world. Their exploitation is largely responsible for the current environmental situation marked by high pollution and abnormal global warming. It becomes crucial to develop "clean" power generation technology. Therefore, a lot of research is devoted to find alternative energy sources to fossil fuels. In this context, micro or minicogeneration from renewable energy sources is an important issue to deal with this problem. The purpose of this paper is to assess the performance of an original configuration of a hotair engine. This kind of engine is thought to be suited for small scale conversion of biomass or solar energy into electricity (up to $\ldots 10 \mathrm{~kW})$.

The compression cylinder of this new hot air engine will be equipped with standard automatic valves according to the conventional Ericsson engine [2], while the expansion cylinder will use actuated valves whose timing is given by one between three different valves command laws. An engine with this configuration is thought to allow the local production of small scale mechanical energy in a very easy and simple way, from non-fossil fuel sources such as biomass or solar energy. This could satisfy local electricity or micro-cogeneration needs.

\section{The Ericsson Engine}

The family of hot air engines is divided in two subgroups: the Stirling engines, invented in 1816 by Robert Stirling, have no valves whereas Ericsson engines, invented in 1833 by John Ericsson have valves in order to isolate the cylinders [2]. The Ericsson engine is defined as an external heat supply reciprocating engine equipped with valves. It is generally composed of a compression cylinder with automatic or actuated valves, a heat recovery exchanger, a hot source heat exchanger, and an expansion cylinder equipped with actuated valves. According to the technological design considered, the Ericsson engine can have different configurations. Figure 1 presents the general Ericsson engine configuration. In some cases, the Ericsson engine is built without any heat recovery exchanger.

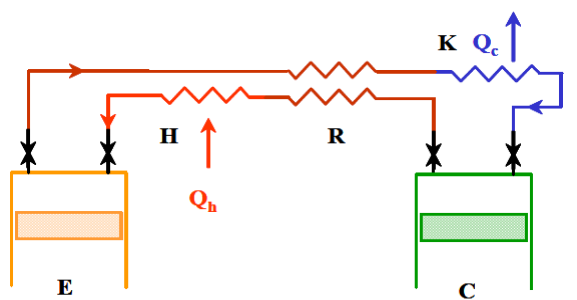

Figure 1. General Ericsson engine configuration. 

[3]:

The elements of the Ericsson engines are the followings

- E: expansion cylinder, equipped with actuated valves;

- H: Heater, heat exchanger between the hot source and the working fluid;

- R: Recuperator, heat recovery exchanger;

- $\mathrm{K}$ : Cooler, heat exchanger between the working fluid and the cold source;

- C: Compression cylinder equipped with automatic or actuated valves.

The valves give some advantages to the Ericsson engine. Amongst them, the most important one is that the heat exchangers are not to be considered as unswept dead volumes whereas the Stirling engine designer is faced to the difficult compromise between heat exchanger transfer area maximization and heat exchanger volume minimization [3].

There is a renewed interest in Ericsson engine since different studies have shown that this engine could have high energy performances, similar of those of Stirling engines, in the low power range, but with lower internal pressure levels [4]. On the other hand, the Ericsson engine is suitable for the production of small scale energy using renewable energy resources such as biomass $[4,5,6]$, or solar energy $[6,7,8]$. Although few in number, some studies are devoted to the analysis of the performance of reciprocating engines based on a Joule cycle with external heat supply $[4,5,6,9]$. Moss \& al. [10] predict a thermal efficiency of $35 \%$ for a reciprocating Joule cycle engine with a pressure ratio of 7.5 and an engine rotational speed of $1000 \mathrm{rpm}$. Wojewoda \& al. [11] studied an external heat supply engine equipped with valves and predicted a thermal efficiency of $25 \%$. Kussul \& al. [12] et Bell $\&$ al. [13] studied the design of an Ericsson engine. Toure \& al. developed a model of the Ericsson engine [9] and show that there is a well-defined operating range for which an engine can generate power. The best efficiency is obtained for pressure ratios comprised between 2 and 3 . Ibsaine \& al. [14,15] show that the so-called "humid" or "wet" cycles are not interesting in the case of regenerative Ericsson engine. Lontsi \& al. developed a dynamic model of an Ericsson engine [16] and show that high rotational speeds affect the energy performance. Creyx \& al. developed detailed models of nonrecuperated Ericsson or Joule cycle reciprocating engines $[4,17,18]$ for solid biomass-fuelled micro-CHP applications. Fula Rojas \& al. have developed studies on thermal and thermodynamic modelling and experimentation of a Joule cycle hot air Ericsson engine [19,20] which allow to determine the conditions under which the in-cylinder heat transfers can improve the performance of the energy system considered.

However, the distribution system of the Ericsson engine introduces some complexity and a non-negligible mechanical energy consumption in order to actuate them. This disadvantage has a detrimental effect on the engine performance. The bash-valve technology is proposed to provide answers and to alleviate this difficulty. The purpose of this article is to compare the energy performance of the engine with expansion cylinder equipped with the bash valve technology with the energy performance of a Joule Ericsson cycle engine.

\section{The bash valve configuration}

There are several types of engine inlet valves mechanism. The focus is on the "bash-valve" configuration. This valve has been widely used in steam piston engines and pneumatic piston engines. The piston itself actuates the opening of the valve when being around the top dead center by the contact between the pin on the piston and the valve tip. When the piston moves to the bottom dead center, the pin loses contact with the valve which closes.

Bash valve have the advantage of great simplicity, for manufacture and operation. Their disadvantages are that their opening and closing times are relatively crudely controlled, compared to other types of valves [21, 22].

Bash valves are usually held closed by the pressure of fluid in the reservoir upstream them. There may be a light spring to assist closing when the reservoir is empty.

The "bash-valve" configuration has been used in steam piston engines and pneumatic piston engines. Especially, it can be noted that this technology has been widely used in the Uniflow steam engines [21, 22, 23].

Figure 2 presents an engine configuration equipped with the bash valve, for which a patent was granted to Harold V. Sturtevant. Steam enters the engine through the red head overhead chamber which is provided with a spring inlet valve, kept closed by steam at high pressure. When the piston is at top dead center, it knocks the inlet valve that opens and the steam enters the cylinder. A solenoid (electromagnetic) coil is energized to delay the closure of the valve. The piston starts moving down, the pressure of the steam which enters the cylinder is sufficient to maintain closed its spring mechanism. This mechanism opens when the piston is in the neighborhood of the bottom dead center, which allows the steam to exhaust. As the piston moves up from the BDC towards the TDC, its spring mechanism remains open, giving rise to a cycle without recompression of the dead volume $[21,22]$. It should be noted that the engine piston that is the subject of this study will not be equipped with the spring mechanism.

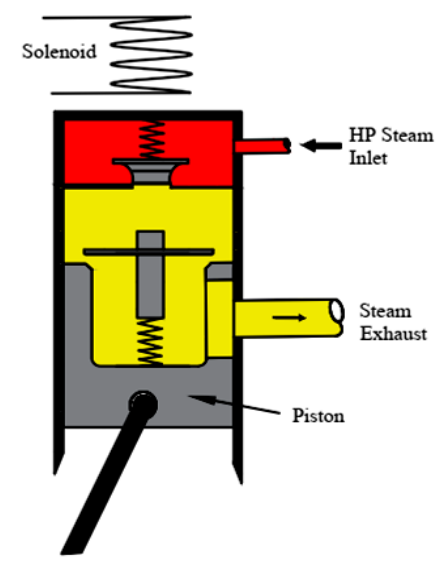

Figure 2. Steam engine with bash-valve patented by $H$. V.Sturtevant [21, 22].

Figure 3 shows a sketch of a piston steam engine equipped with a simple bash valve [24].

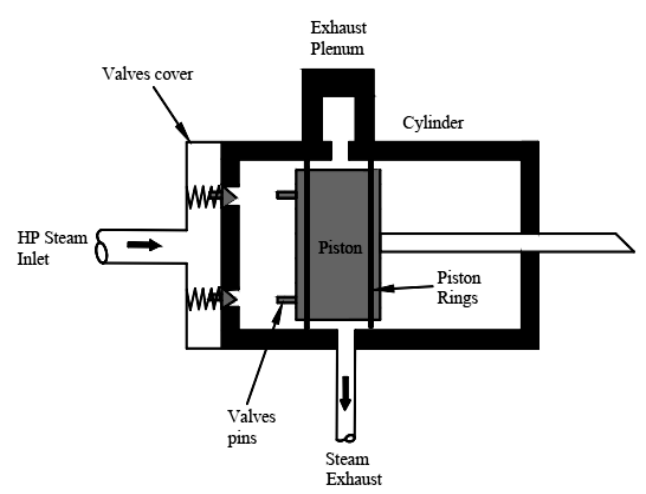

Figure 3. OSE Engine project by Marcin Jakubowski [24]. 
Figure 4 shows a sketch of a piston steam engine equipped with a ball valve. The engine was built by the Australian National University (ANU) in 1988-1989 [25, 26]. The cylinder heads of the engine named "White Cliffs Solar steam engine", contain the steam inlet ball valves which are operated by pins in the crown of the piston.

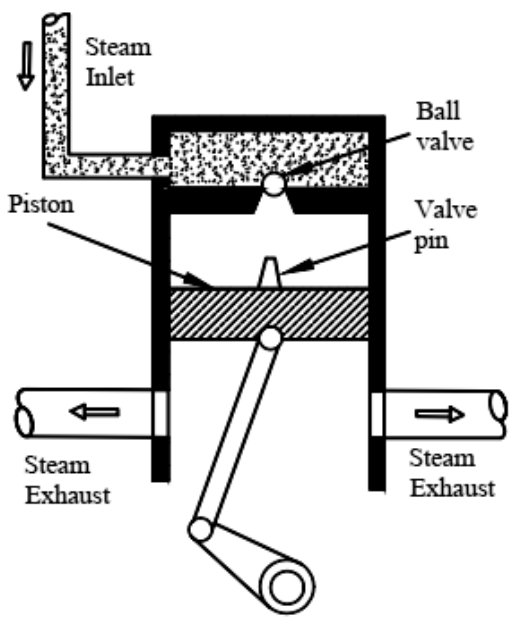

Figure 4. The ANU reciprocating steam engine bash valve [25].

The interest of the present article is to study the performance of a new machine that combines both the benefits of an Ericsson engine and of the bash valve technology to meet the current energy needs. This study is based on a modelling approach from dimensionless parameters [9]. It allows to size this type of engine for a given application and to determine the operating pressure in the heater according to the geometrical and thermal characteristics of the engine.

4. Presentation of the three valves command laws studied

- The valve command law 1: Engine with expansion cylinder equipped with a simple bash valve. The exhaust port is open at the BDC. This technology, corresponding to the UNIFLOW configuration, is interesting because of its great simplicity for manufacture and operation;

- The valve command law 2: Engine with expansion cylinder equipped with the bash valve with delay of inlet valve closing. The delay of the inlet valve closing corrects and improves the energetic performances of the valve command law 1 . The exhaust port is open at the BDC;

- The valve command law 3: Engine with expansion cylinder equipped with inlet and outlet valves driven with the same delay of valve closing. The delay is settled such as the pressure in the cylinder at the TDC, resulting from the re-compression of the dead volume, is equal to the inlet pressure.

\section{Global analysis of the system}

5.1. Configuration of the engine with expansion cylinder equipped with a simple bash valve according to the valve command law 1

The system considered in this part of the study is based on the engine configuration of the Figure 5. The compression cylinder $\mathrm{C}$ is equipped with conventional automatic valves, while the expansion cylinder $\mathrm{E}$ uses a simple bash valve technology according to command law 1. Air enters the compression cylinder with temperature $T_{k}$ and atmospheric pressure, is compressed and exhausted at temperature $T_{c r}$ to be preheated in the counter-flow heat recovery exchanger $\mathrm{R}$ up to temperature $T_{r h}$. It then passes through the heater $\mathrm{H}$ where it is heated. Hot air at the temperature $T_{h}$ enters the cylinder E where it is expanded until the piston uncovers the exhaust port at the BDC. The expanded air at temperature $T_{e r}$ then passes into the exchanger $\mathrm{R}$ to heat the air entering the heater, before being released into the atmosphere at a temperature $T_{r k}$ well below $T_{e r}$. The inlet valve V1 is a "bash valve" type and the valves V2 are ordinary automatic or actuated valves.

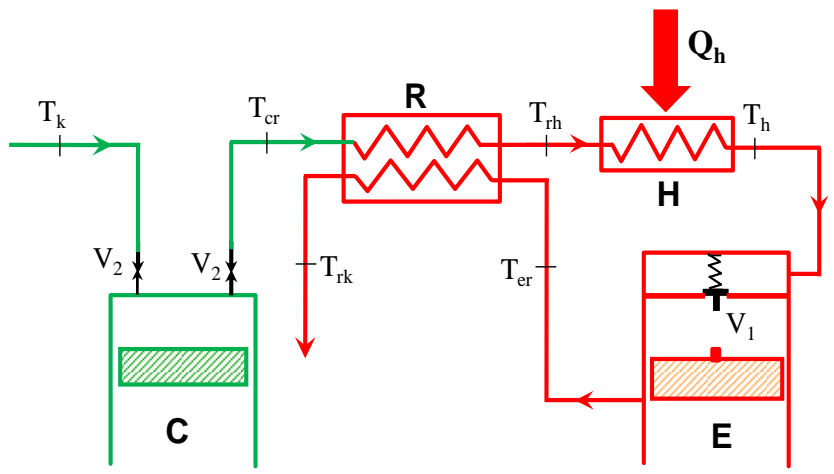

Figure 5. Principle of the engine with expansion cylinder valves driven according to law 1.

5.2. Configuration of the engine with expansion cylinder equipped with the bash valve with delay of inlet valve closing according to the valve command law 2

The system considered in the second part of the study is based on the engine configuration of the Figure 6 . The operation of the engine with expansion cylinder according to law 2 is almost similar to that presented for law 1 (§ 5.1), with the only difference that the expansion cylinder is equipped with the bash valve with delay of inlet valve closing. When the piston knocks the inlet valve, the delay can be created either by a solenoid $(\mathrm{S})$ coil that will be energized to maintain the valve temporarily open, or by a pneumatic system (P) associated with the bash valve to hold the valve temporarily open. This pneumatic system can be very simply energized by the pressure of the working fluid delivered by the compression C.

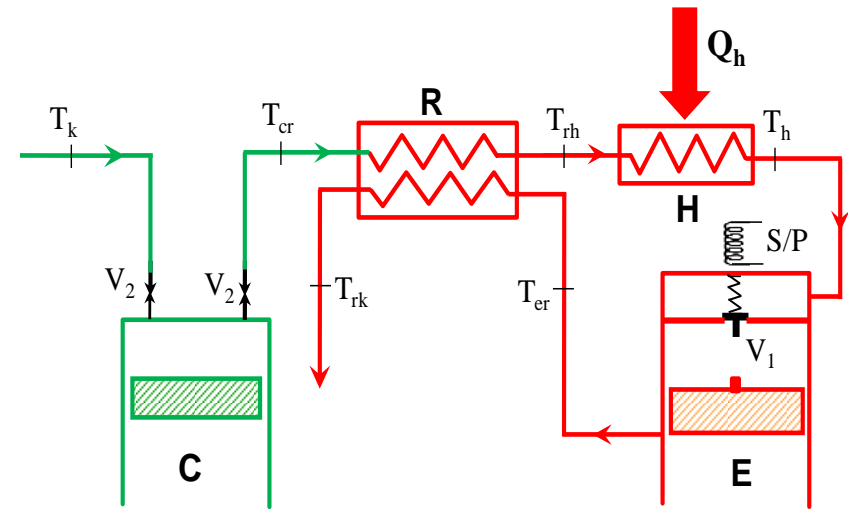

Figure 6-Principle of the engine with expansion cylinder valves driven according to law 2

5.3. Configuration of the engine with expansion cylinder equipped with inlet and outlet valves driven with the same delay of valve closing according to the valve command law 3

The system considered in this part of the study is based on the engine configuration of the Figure 7. The compression cylinder $\mathrm{C}$ is equipped with conventional automatic valves $\mathrm{V} 2$, 
while the expansion cylinder E uses valves opening at piston dead centre (TDC for inlet valve and BDC for outlet valve) and closing with the same delay, according to command law 3 . The actuated valves V1 have a great advantage when used for example in the case of a liquid piston engine whose liquid columns operate in phase opposition. The opening of inlet valve of one of the cylinder corresponding to the opening of exhaust valve of the other cylinder, and vice versa. It is technologically easy with the actuated valves of this system to have the same delay in closing of the inlet and the exhaust valves.

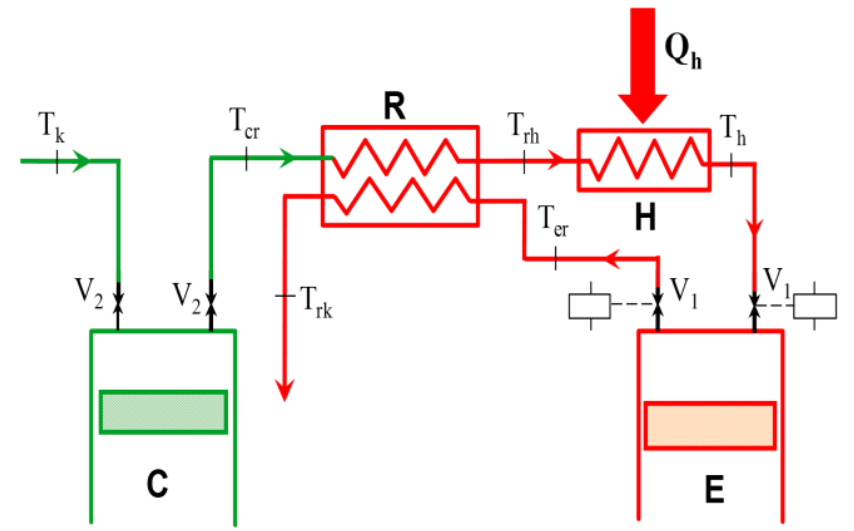

Figure 7. Principle of the engine with expansion cylinder valves driven according to law 3.

\subsection{General assumptions of the model}

The general assumptions of the model are:

- Compression and expansion of the working fluid are considered isentropic thermodynamic processes;

- The working fluid is air considered as a perfect gas with constant specific heat;

- The viscous frictions in the working fluid are neglected in all calculations. The intake and discharge are supposed isobar: Pressure losses through the valves are neglected. The fluid flows through the heat exchangers are also assumed to be isobar.

\subsection{Dimensionless quantities}

For each state $i$ of the working fluid in the engine, the following dimensionless quantities are defined:

- the dimensionless pressure $\beta_{i}=p_{i} / p_{k}$; by extension, $B=p_{h} / p_{k}$

- the dimensionless temperature $\theta_{i}=T_{i} / T_{k}$; by extension, $\Theta=T_{h} / T_{k}$

- the dimensionless cylinder capacity $\varphi_{i}=V_{i} / V_{C}$; by extension, $\Phi=V_{E} / V_{C}$

- the dimensionless mass or mass flow rate

$\delta_{i}=m_{i} r T_{k} /\left(p_{k} V_{C}\right)=\dot{m}_{i} r T_{k} /\left(n p_{k} V_{C}\right)$

$=\beta_{i} \varphi_{i} / \theta_{i}$

- the dimensionless indicated work or power

- $\quad \Pi_{i}=W_{i} /\left(p_{k} V_{C}\right)=\dot{W}_{i} /\left(n p_{k} V_{C}\right)=$ $\oint p_{i} d V_{i} /\left(p_{k} V_{C}\right)=\oint \beta_{i} d \varphi_{i} i=E$ ou $C$

- the net dimensionless mechanical power $\Pi_{n e t}=\Pi_{E}-\Pi_{C}$

- the dimensionless heat exchanged in the heater $\Pi_{t h}=$ $Q_{t h} /\left(p_{k} V_{C}\right)$

- the indicated thermal efficiency $\eta_{t h}=$ $\left(\Pi_{E}-\Pi_{C}\right) / \Pi_{t h}=\Pi_{n e t} / \Pi_{t h}$

\subsection{Detailed modeling of the compression}

Figure 8 presents the dimensionless indicated diagram $(\beta, \varphi)$ of the compressor. The compressor relative dead space is defined as $\mu_{C}=V_{C 3}-V_{C}$ with $V_{C}=V_{C 1}-V_{C 3}$ the compression cylinder capacity. The assumption related to the compression cycle made of two isentropic processes and two isobaric processes allows to compute the dimensionless temperatures, volumes, pressures and mass (or mass flow rates) for each state of the compression cycle (Table 1). In the relations, $\gamma=c_{p} / c_{v}$ is the specific heat ratio and $k=$ $r / c_{p}=(\gamma-1) / \gamma$.

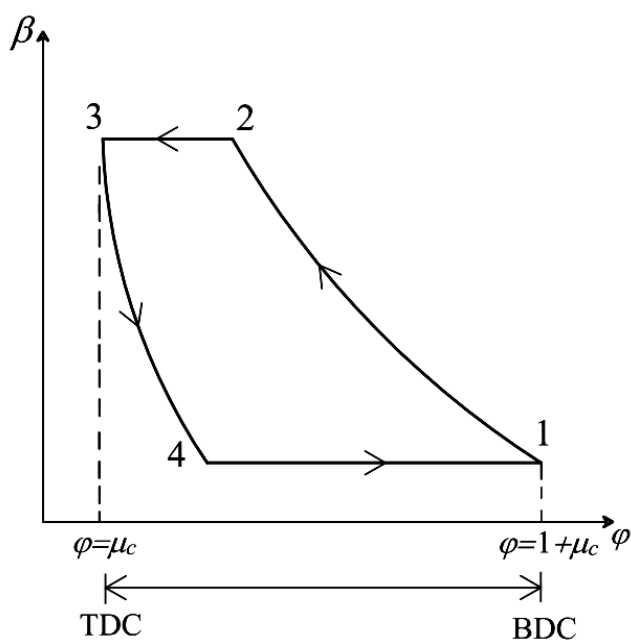

Figure 8. Dimensionless indicated diagram of the compression cylinder.

The dimensionless mass flow rate through the compressor is given by:

$$
\delta_{C}=\delta_{C 1}-\delta_{C 4}=1-\mu_{C}\left(B^{\frac{1}{\gamma}}-1\right)
$$

Table 1. Dimensional quantities corresponding to the different states of the indicated diagram $(\beta, \varphi)$ of the compression cylinder of Figure 8.

\begin{tabular}{c|c|c|c|c}
\hline Quantity & State 1 & State 2 & State 3 & State 4 \\
\hline$\theta_{i}$ & 1 & $B^{k}$ & $B^{k}$ & 1 \\
$\varphi_{i}$ & $1+\mu_{C}$ & $B^{\frac{-1}{\gamma}}\left(1+\mu_{C}\right)$ & $\mu_{C}$ & $B^{\frac{1}{\gamma}} \mu_{C}$ \\
$\beta_{i}$ & 1 & $B$ & $B$ & 1 \\
$\delta_{i}$ & $1+\mu_{C}$ & $1+\mu_{C}$ & $B^{\frac{1}{\gamma}} \mu_{C}$ & $B^{\frac{1}{\gamma}} \mu_{C}$ \\
\hline
\end{tabular}

The compression indicated power is a function of the mass flow rate and the enthalpy difference between states 1 and 2 of the indicated diagram. Its dimensionless expression is given by:

$$
\Pi_{C}=\frac{1}{k}\left(1-\mu_{C}\left(B^{\frac{1}{\gamma}}-1\right)\right)\left(B^{k}-1\right)
$$

It can be demonstrated that this result may also be computed as:

$$
\Pi_{C}=\oint_{C} \beta d \varphi
$$


5.7. Modeling of the engine with expansion cylinder valves driven according to law 1

\subsubsection{Detailed modeling of the expansion cylinder}

Figure 9 shows the dimensionless indicator diagram $(\beta, \varphi)$ of the expansion machine with valves driven according to law 1: "bash valve without any delay". The relative dead volume is defined as $\mu_{E}=V_{E 3} / V_{E}$ with $V_{E}=V_{E 1}-V_{E 3}$ the expansion cylinder capacity.

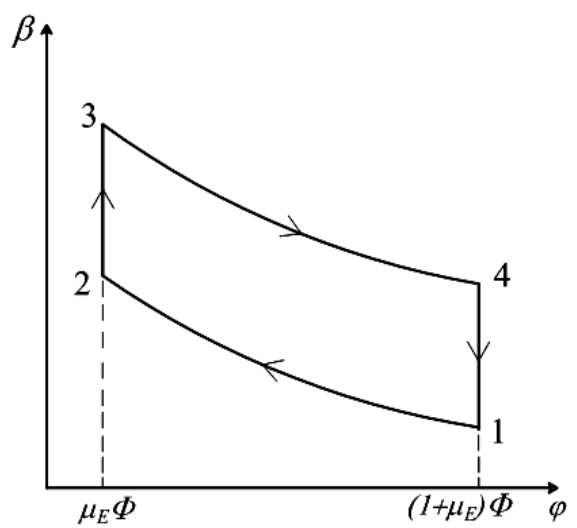

Figure 9. Dimensionless indicated diagram $(\beta, \varphi)$ of the engine with expansion cylinder valves driven according to law 1.

From state 1 to 2 , the piston compresses the residual working fluid in the cylinder up to pressure $p_{2}$. At TDC, the piston opens the "bash valve" and the pressure suddenly rises up to the maximum pressure $p_{3}$. During this process, some working fluid flows from the heater into the expansion cylinder. The "bash valve" immediately closes as soon as the piston begins its motion towards the BDC and the working fluid is expanded. At TDC, the piston uncovers the exhaust port and the pressure falls from pressure $p_{4}$ to the downstream pressure $p_{1}$ while some working fluid flows out of the expansion cylinder.

The calculation of the temperatures of the different states in the expansion cylinder results from a system of 4 equations corresponding to the isentropic expansion 3-4, the isentropic compression 1-2, the energy balance corresponding to the mixing of the air in the cylinder at maximum temperature and the inlet air (process 2-3), the energy balance corresponding to the exhaust process 4-1 at a variable temperature. The solution of this set of equations is given by Eq. (4). In these relations, $m_{E}=\left(1+\mu_{E}\right) / \mu_{E}$.

$$
\left.\begin{array}{c}
\theta_{E 1}=\frac{\gamma \Theta\left(B^{1 / \gamma}-m_{E}\right)}{B-m_{E}^{\gamma}} \\
\theta_{E 2}=m_{E}^{\gamma-1} \frac{\gamma \Theta\left(B^{1 / \gamma}-m_{E}\right)}{B-m_{E}^{\gamma}} \\
\theta_{E 3}=B^{k} \frac{\gamma \Theta\left(B^{1 / \gamma}-m_{E}\right)}{B-m_{E}^{\gamma}} \\
\theta_{E 4}=\frac{B^{k}}{m_{E}^{\gamma-1}} \frac{\gamma \Theta\left(B^{1 / \gamma}-m_{E}\right)}{B-m_{E}^{\gamma}}
\end{array}\right\}
$$

Table 2 gives the dimensionless states of the working fluid in the expansion cylinder resulting from the solution of this set of equations.

Table 2. Dimensional quantities corresponding to the different states of the indicated diagram $(\beta, \varphi)$ of the expansion cylinder of Figure 9.

\begin{tabular}{c|c|c|c|c}
\hline Quantity & State 1 & State 2 & State 3 & State 4 \\
\hline$\theta_{i}$ & See Eq. (4) & See Eq. (4) & See Eq. (4) & See Eq. (4) \\
$\varphi_{i}$ & $\left(1+\mu_{E}\right) \Phi$ & $\mu_{E} \Phi$ & $\mu_{E} \Phi$ & $\left(1+\mu_{E}\right) \Phi$ \\
$\beta_{i}$ & 1 & $m_{E}^{\gamma}$ & $B$ & $\frac{B}{m_{E}^{\gamma}}$ \\
$\delta_{i}$ & See Eq. (5) & See Eq. (5) & See Eq. (6) & See Eq. (6) \\
\hline
\end{tabular}

The dimensionless masses are given by Eqs. (5) and (6):

$$
\begin{aligned}
& \delta_{E 1}=\delta_{E 2}=\left(1+\mu_{E}\right) \frac{\Phi}{\Theta} \frac{\left(B-m_{E}^{\gamma}\right)}{\gamma\left(B^{1 / \gamma}-m_{E}\right)} \\
& \delta_{E 3}=\delta_{E 4}=\frac{\mu_{E} \Phi}{\Theta} \frac{\left(B-m_{E}^{\gamma}\right)}{\gamma B^{k-1}\left(B^{1 / \gamma}-m_{E}\right)}
\end{aligned}
$$

The dimensionless mass flow rate in the expansion cylinder is obtained as the difference between the dimensionless mass at states 3 and 2 or at states 4 and 1 :

$$
\delta_{E}=\frac{\Phi}{\Theta} \frac{\mu_{E}}{\gamma}\left(B-m_{E}^{\gamma}\right)
$$

The expansion indicated power can be computed as:

$$
\Pi_{E}=\oint \beta d \varphi
$$

This yields the following result:

$$
\Pi_{E}=\frac{\mu_{E} \Phi}{\gamma-1}\left(B-m_{E}\right)\left(1-\frac{1}{m_{E}^{\gamma-1}}\right)
$$

During the sudden exhaust process $4-1$, the temperature continuously decreases from temperature $T_{4}$ to temperature $T_{l}$. It can be demonstrated that the mean exhaust temperature is given by Eq. (10):

$$
\bar{\theta}_{e r}=\frac{\Theta}{m_{E}^{\gamma-1}}
$$

\subsubsection{Modeling of the whole engine}

The engine operates only if the mass flow rate through the compression cylinder is the same as the mass flow rate through the expansion cylinder, that is if:

$$
\delta_{E}=\delta_{C}
$$

This yields: 
$\Phi=\Theta \frac{\gamma}{\mu_{E}} \frac{1-\mu_{C}\left(B^{1 / \gamma}-1\right)}{\left(B-m_{E}^{\gamma}\right)}$

The dimensionless mechanical net power produced by the Ericsson engine is simply given by:

$$
\Pi_{n e t}=\Pi_{E}-\Pi_{C}
$$

In this equation the expansion power is given by Eq. (9) and the compression power is given by Eq. (2). The thermal power supplied to the working fluid by the heater $\mathrm{H}$ can be computed as follows:

$$
\Pi_{t h}=\frac{\delta_{E}}{k}\left(\Theta-\theta_{r h}\right)
$$

This expression contains the temperature at the inlet of the heater which can be easily computed according to the heat recovery exchanger effectiveness:

$$
\theta_{r h}=\varepsilon_{R}\left(\frac{\Theta}{m_{E}^{\gamma-1}}-B^{k}\right)+B^{k}
$$

The effectiveness of the recovery heat exchanger is defined by equation (16):

$$
\varepsilon_{R}=\frac{\theta_{r h}-\theta_{k}}{\bar{\theta}_{e r}-\theta_{k}}
$$

The following expression is then obtained for the heater thermal power:

$$
\begin{gathered}
\Pi_{t h}=\frac{\Phi}{\Theta} \frac{\mu_{E}}{k \gamma}\left(B-m_{E}^{\gamma}\right) \\
\times\left[\Theta-\varepsilon_{R}\left(\frac{\Theta}{m_{E}^{\gamma-1}}-B^{k}\right)+B^{k}\right]
\end{gathered}
$$

The indicated thermal efficiency is the ratio of the net mechanical power Eq. (13) to the thermal power Eq. (17):

$$
\eta_{t h}=\frac{\Pi_{n e t}}{\Pi_{t h}}
$$

\subsection{Modeling of the engine with expansion cylinder valves} driven according to law 2

The modification in the configuration of this engine does not concern the compression cylinder. Thus, the parameters calculated in section $\S 5.6$ remain unchanged.

\subsubsection{Detailed modeling of the expansion cylinder}

Figure 10 shows the dimensionless indicator diagrams $(\beta, \varphi)$ of the expansion machine with valves driven according to the bash valve technology with delay of inlet valve closing.

The relative dead volume is defined as $\mu_{E}=V_{E 3} / V_{E}$ with $V_{E}=V_{E 1}-V_{E 3}$. State 3 to 3 ' represented by $\alpha$ corresponds to the setting parameter of the inlet valve closing where $\alpha=$ $\left(V_{E 3^{\prime}}-V_{E 3}\right) / V_{E}$. If $\alpha=0$, the results obtained correspond to the command law 1. The calculation of the temperatures of the different states in the expansion cylinder results from a system of 5 equations corresponding to the isobaric admission 3-3', to an isentropic expansion $3^{\prime}-4$, to the energy balance corresponding to the sudden exhaust at variable temperature transformation 4-1, at a recompression of the residual fluid 12 , at the energy balance corresponding to the mixture between the air in the cylinder at the maximum temperature and the air admitted by the transformation 2-3. In these relations, $m_{E}=$ $\left(1+\mu_{E}\right) / \mu_{E}$ and $w_{E}=\left(\alpha+\mu_{E}\right) /\left(1+\mu_{E}\right)$.

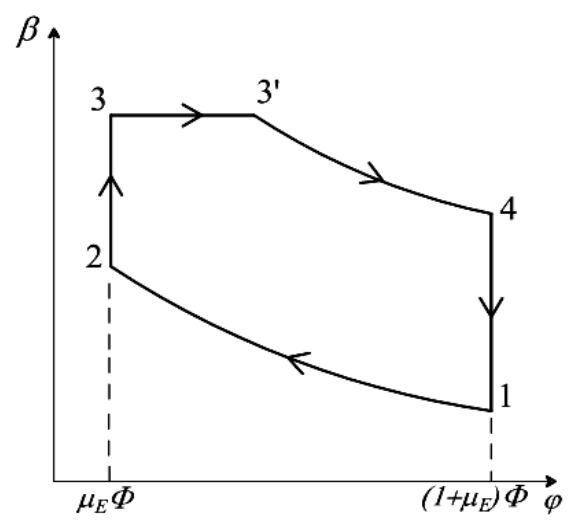

Figure 10. Dimensionless indicated diagram $(\beta, \varphi)$ of the engine with expansion cylinder valves driven according to law 2 .

Table 3 gives the dimensionless states of the working fluid in the expansion cylinder resulting from the solution of this set of equations.

$$
\left.\begin{array}{c}
\theta_{E 1}=\frac{\gamma \Theta\left[\alpha+\mu_{E}\left(1-m_{E} B^{-1 / \gamma}\right)\right]}{\left(B-m_{E}^{\gamma}\right) B^{-1 / \gamma} \mu_{E}+\alpha \gamma B^{k}} \\
\theta_{E 2}=\frac{m_{E}^{\gamma-1} \gamma \Theta\left[\alpha+\mu_{E}\left(1-m_{E} B^{-1 / \gamma}\right)\right]}{\left(B-m_{E}^{\gamma}\right) B^{-1 / \gamma} \mu_{E}+\alpha \gamma B^{k}} \\
\theta_{E 3^{\prime}}=\frac{B^{k} \gamma \Theta\left[\alpha+\mu_{E}\left(1-m_{E} B^{-1 / \gamma}\right)\right]}{\left(B-m_{E}^{\gamma}\right) B^{-1 / \gamma} \mu_{E}+\alpha \gamma B^{k}} \\
\frac{B^{k} \mu_{E} \gamma \Theta\left[\alpha+\mu_{E}\left(1-m_{E} B^{-1 / \gamma}\right)\right]}{\left[\left(\alpha+\mu_{E}\right)\left[\left(B-m_{E}^{\gamma}\right) B^{-1 / \gamma} \mu_{E}+\alpha \gamma B^{k}\right]-\right]} \\
\alpha \gamma B^{k}\left[\alpha+\mu_{E}\left(1-m_{E} B^{-1 / \gamma}\right)\right] \\
\theta_{E 4}=\frac{B^{k} w_{E}^{\gamma-1} \gamma \Theta\left[\alpha+\mu_{E}\left(1-m_{E} B^{-1 / \gamma}\right)\right]}{\left(B-m_{E}^{\gamma}\right) B^{-1 / \gamma} \mu_{E}+\alpha \gamma B^{k}}
\end{array}\right\}
$$
(22):

The dimensionless masses are given by Eq. (20), (21) and

$$
\begin{aligned}
& \delta_{E 1}=\delta_{E 2} \\
& =\frac{\left(1+\mu_{E}\right) \Phi\left[\left(B-m_{E}^{\gamma}\right) B^{-1 / \gamma} \mu_{E}+\alpha \gamma B^{k}\right]}{\gamma \Theta\left[\alpha+\mu_{E}\left(1-m_{E} B^{-1 / \gamma}\right)\right]} \\
& \delta_{E 3 \prime}=\delta_{E 4} \\
& =\frac{\left(\alpha+\mu_{E}\right) \Phi\left[\left(B-m_{E}^{\gamma}\right) B^{-1 / \gamma} \mu_{E}+\alpha \gamma B^{k}\right]}{B^{k-1} \gamma \Theta\left[\alpha+\mu_{E}\left(1-m_{E} B^{-1 / \gamma}\right)\right]}
\end{aligned}
$$




$$
=\frac{B \Phi \mu_{E}\left[\begin{array}{c}
\left(\alpha+\mu_{E}\right)\left[\left(B-m_{E}^{\gamma}\right) B^{-1 / \gamma} \mu_{E}+\alpha \gamma B^{k}\right] \\
-\alpha \gamma B^{k}\left[\alpha+\mu_{E}\left(1-m_{E} B^{-1 / \gamma}\right)\right]
\end{array}\right]}{B^{k} \mu_{E} \gamma \Theta\left[\alpha+\mu_{E}\left(1-m_{E} B^{-1 / \gamma}\right)\right]}
$$

Table 3. Dimensional quantities corresponding to the different states of the indicated diagram $(\beta, \varphi)$ of the expansion cylinder of Figure 10.

\begin{tabular}{c|c|c|c|c|c}
\hline Quantity & State 1 & State 2 & State 3 & State 4 & State 3' \\
\hline$\theta_{i}$ & $\begin{array}{c}\text { See Eq. } \\
(19)\end{array}$ & $\begin{array}{c}\text { See Eq. } \\
(19)\end{array}$ & $\begin{array}{c}\text { See Eq. } \\
(19)\end{array}$ & See Eq. (19) & See Eq. (19) \\
$\varphi_{i}$ & $\left(1+\mu_{E}\right) \Phi$ & $\mu_{E} \Phi$ & $\mu_{E} \Phi$ & $\left(1+\mu_{E}\right) \Phi$ & $\varphi_{E 3^{\prime}}=\left[\Phi\left(\alpha+\mu_{E}\right)\right]$ \\
$\beta_{i}$ & 1 & $m_{E}^{\gamma}$ & $B$ & $\beta_{E 4}=w_{E}^{\gamma} B$ & $\beta_{E 3^{\prime}}=B$ \\
$\delta_{i}$ & $\begin{array}{c}\text { See Eq. } \\
(20)\end{array}$ & $\begin{array}{c}\text { See Eq. } \\
(20)\end{array}$ & $\begin{array}{c}\text { See Eq. } \\
(22)\end{array}$ & See Eq. (21) & See Eq. (21) \\
\hline
\end{tabular}

The dimensionless mass flow rate in the expansion cylinder is obtained as the difference between the dimensionless mass at states 3 ' and states 2 :

$$
\delta_{E}=\frac{B \Phi\left(\alpha+\mu_{E}\right)}{\theta_{E 3 \prime}}-\frac{\Phi m_{E}^{\gamma} \mu_{E}}{\theta_{E 2}}
$$

The expression of the expansion indicated power is identical to that given by Eq. (8).

This yields the following result:

$$
\begin{array}{r}
\Pi_{E}=\Phi\left[B \alpha+B \frac{\alpha+\mu_{E}}{\gamma-1}\left(1-\left(\frac{\alpha+\mu_{E}}{1+\mu_{E}}\right)^{\gamma-1}\right)\right. \\
\left.-\frac{m_{E}^{\gamma} \mu_{E}}{\gamma-1}\left(1-\frac{1}{m_{E}^{\gamma-1}}\right)\right]
\end{array}
$$

\subsubsection{Modeling of the whole engine}

The engine operates only if the mass flow rate through the compression cylinder is the same as the mass flow rate through the expansion cylinder, Eq (11).

This yields:

$$
\Phi=\frac{1-\mu_{C}\left(B^{1 / \gamma}-1\right)}{\frac{B\left(\alpha+\mu_{E}\right)}{\theta_{E 3 \prime}}-\frac{m_{E}^{\gamma} \mu_{E}}{\theta_{E 2}}}
$$

The expression of the dimensionless mechanical net power is given by Eq. (13), with $\Pi_{E}$ given by Eq. (24) and $\Pi_{C}$ given by Eq. (2). The expression of the heater thermal power is identical to that given by Eq. (14).

The indicated thermal efficiency is given by :

$$
\eta_{t h}=\frac{\Pi_{n e t}}{\Pi_{t h}}
$$

It can be easily verified that equations (19) to (26) give the same results as equations (4) to (18) if the delay of inlet valve closing is set to zero: $\alpha=0$.

\subsection{Modeling of the engine with expansion cylinder valves driven according to the law 3}

The modification in the configuration of this engine does not concern the compression cylinder. Thus, the parameters calculated in section $\S 5.6$ remain unchanged.

\subsubsection{Detailed modeling of the expansion cylinder}

Figure 11 shows the dimensionless indicator diagram $(\beta, \varphi)$ of the expansion cylinder in the case of law 3 .

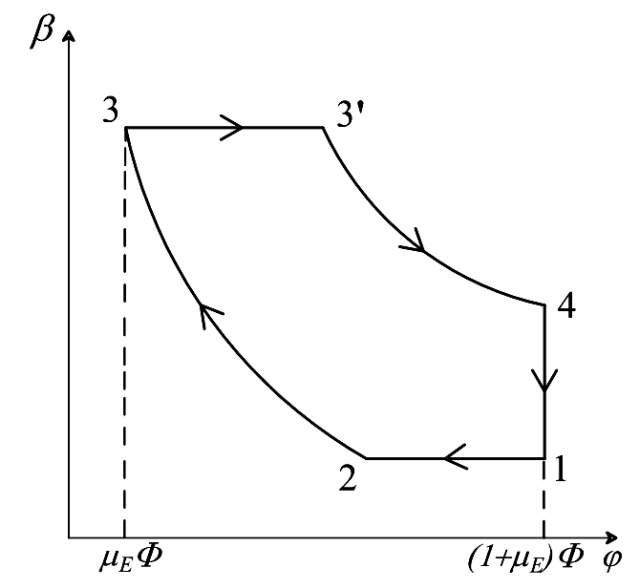

Figure 11. Dimensionless indicated diagram $(\beta, \varphi)$ of the engine with expansion cylinder valves driven according to law 3.

The relative dead volume is defined as $\mu_{E}=V_{E 3} / V_{E}$ with $V_{E}=V_{E 1}-V_{E 3}$ and $\alpha=\left(V_{E 3},-V_{E 3}\right) / V_{E}=\left(V_{E 1}-V_{E 2}\right) / V_{E}$ the setting parameter of the inlet and exhaust valves closing.

This parameter of the delay of the inlet and exhaust valves closing of the expansion cylinder is related to the pressure ratio and the relative dead volume of the cylinder:

$$
\alpha=1+\mu_{E}\left(1-B^{1 / \gamma}\right)
$$

The calculation of the temperatures of the different states in the expansion cylinder results from a system of 3 equations corresponding to the isobaric admission 3-3', to an isentropic expansion 3 '-4, to the energy balance corresponding to the mixture between the air in the cylinder at the maximum temperature and the air admitted by the transformation $2-3$, to the energy balance corresponding to the sudden exhaust at variable temperature transformation 4-1 and isobaric 1-2. In these relations, $m_{E}=\left(1+\mu_{E}\right) / \mu_{E}, w_{E}=\left(\alpha+\mu_{E}\right) /\left(1+\mu_{E}\right)$ et $n_{E}=\left(1+\mu_{E}-\alpha\right) / \mu_{E}$.

$$
\left.\begin{array}{c}
\theta_{E 2}=\theta_{E 1}=\Theta B^{-k} \\
\theta_{E 3}=\theta_{E 3 \prime}=\Theta \\
\theta_{E 4}=\Theta\left[\frac{1+\mu_{E}\left(2-B^{\frac{1}{\gamma}}\right)}{1+\mu_{E}}\right]^{\gamma-1}
\end{array}\right\}
$$

Table 4 gives the dimensionless states of the working fluid in the expansion cylinder resulting from the solution of this set of equations. 
Table 4. Dimensional quantities corresponding to the different states of the indicated diagram $(\beta, \varphi)$ of the expansion cylinder of Figure 11.

\begin{tabular}{c|c|c|c|c|c}
\hline $\begin{array}{c}\text { Quan- } \\
\text { tity }\end{array}$ & State 1 & State 2 & State 3 & State 4 & State 3' \\
\hline$\theta_{i}$ & $\begin{array}{c}\text { See Eq. } \\
(28)\end{array}$ & See Eq. (28) & $\begin{array}{c}\text { See Eq. } \\
(28)\end{array}$ & See Eq. (28) & $\begin{array}{c}\text { See Eq. } \\
(28)\end{array}$ \\
$\varphi_{i}$ & $\left(1+\mu_{E}\right) \Phi$ & $\Phi\left(1+\mu_{E}-\alpha\right)$ & $\mu_{E} \Phi$ & $\left(1+\mu_{E}\right) \Phi$ & $\Phi\left(\alpha+\mu_{E}\right)$ \\
$\beta_{i}$ & 1 & $m_{E}^{\gamma}$ & $B$ & $\beta_{E 4}=w_{E}^{\gamma} B$ & $\beta_{E 3 \prime}=B$ \\
$\delta_{i}$ & $\begin{array}{c}\text { See Eq. } \\
(29)\end{array}$ & See Eq. (30) & $\begin{array}{c}\text { See Eq. } \\
(30)\end{array}$ & See Eq. (31) & $\begin{array}{c}\text { See Eq. } \\
(31)\end{array}$ \\
\hline
\end{tabular}
(31):

The dimensionless masses are given by Eq. (29), (30) and

$$
\begin{aligned}
& \delta_{E 1}=\frac{B^{k} \Phi\left(1+\mu_{E}\right)}{\Theta} \\
& \delta_{E 2}=\delta_{E 3}=\frac{B \Phi \mu_{E}}{\Theta} \\
& \delta_{E 3^{\prime}}=\delta_{E 4}=\frac{B \Phi\left[1+\mu_{E}\left(2-B^{\frac{1}{\gamma}}\right)\right]}{\Theta}
\end{aligned}
$$

The dimensionless mass flow rate in the expansion cylinder is obtained as the difference between the dimensionless mass at states 3 ' and 2 or states 4 and 1:

$$
\delta_{E}=\frac{B \Phi\left[1+\mu_{E}\left(1-B^{\frac{1}{\gamma}}\right)\right]}{\Theta}
$$

The expression of the expansion indicated power is computed according Eq. (8). This yields the following result:

$$
\begin{array}{r}
\Pi_{E}=\Phi\left[B \alpha+\left(\frac{B\left(\alpha+\mu_{E}\right)}{\gamma-1}\left(1-\left(\frac{\alpha+\mu_{E}}{1+\mu_{E}}\right)^{\gamma-1}\right)\right)\right. \\
\left.-\alpha-\left(\frac{B \mu_{E}}{\gamma-1}\left(1-\frac{1}{n_{E}^{\gamma-1}}\right)\right)\right]
\end{array}
$$

\subsubsection{Modeling of the whole engine}

The Ericsson engine operates only if the mass flow rate through the compression cylinder is the same as the mass flow rate through the expansion cylinder, Eq (11).

This yields:

$$
\Phi=\frac{\Theta}{B} \frac{1-\mu_{C}\left(B^{1 / \gamma}-1\right)}{1+\mu_{E}\left(1-B^{1 / \gamma}\right)}
$$

The expression of the dimensionless mechanical net power is given by Eq. (13), with $\Pi_{E}$ given by Eq. (33) and $\Pi_{C}$ given by Eq. (2).

The expression of the heater thermal power is identical to that given by Eq. (14).

The expression of the indicated thermal efficiency is identical to that given by Eq. (18).

\section{RESULTS}

\subsection{Dimensionless mass flow rate}

\subsubsection{Compression cylinder}

Figure 12 presents the evolution of the dimensionless air flow rate $\delta_{C}$ of the compression cylinder as a function of the dead volume $\mu_{C}$ and the pressure ratio $B$ Eq. (1). It is found that the air flow rate decreases as the dead volume of the compression cylinder increases. This technically unavoidable dead volume is therefore detrimental to the performance of the compression cylinder. In the absence of dead volume, the air flow rate of the compression cylinder, and therefore of the complete engine, will only depend on the parameters of the admission air in the cylinder (ambient pressure and temperature), the volume swept by the piston and the rotational speed of the engine.

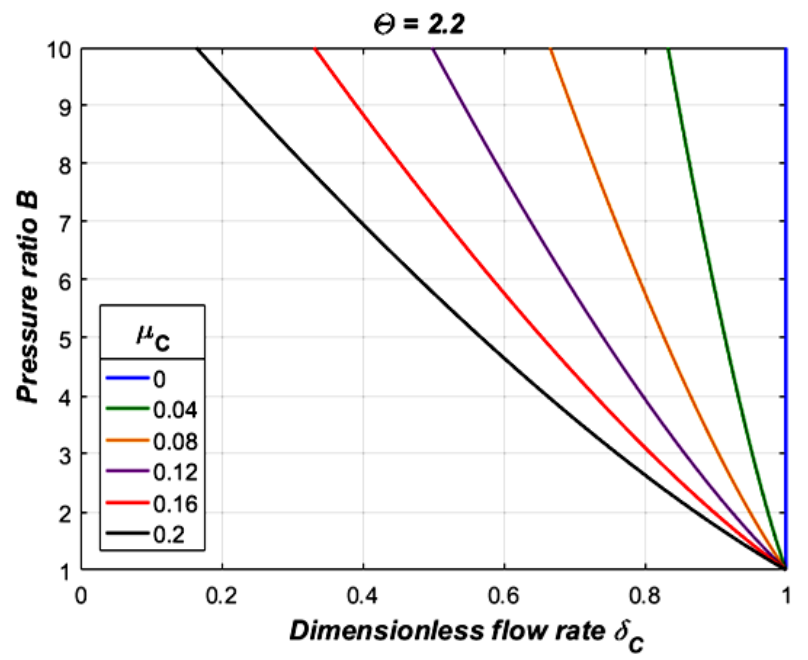

Figure 12. Evolution of the dimensionless air flow rate of the compression cylinder depending on the pressure ratio for different values of $\mu_{C}$.

It is also noted that as the pressure ratio increases, the flow rate decreases. In view of the results of Figure 12, we can realize that it is better to minimize the dead volume as much as possible.

The expression of $\delta_{C}$ shows that in the theoretical case, when $\mu_{C}$ is zero, the dimensionless flow rate of the compression cylinder is equal to 1 whatever the value of the pressure ratio. The dimensionless flow rate is also equal to 1 when the pressure ratio is unitary, whatever the dead volume. This explains the fact that all the curves obtained in Figure 12 start from point 1 .

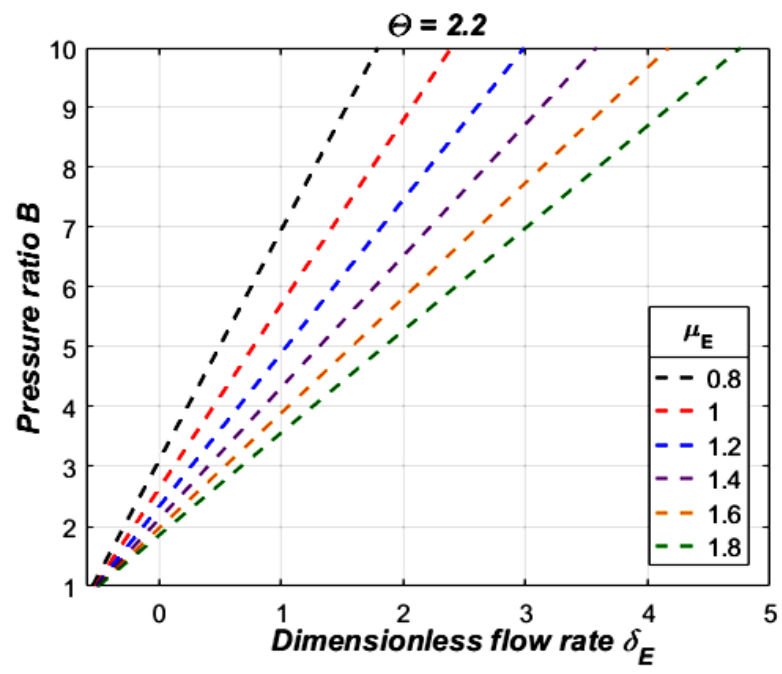

Figure 13. Evolution of the dimensionless air flow rate of the expansion cylinder of the engine according to law 1 depending on the pressure ratio for different values of $\mu_{E}$. 


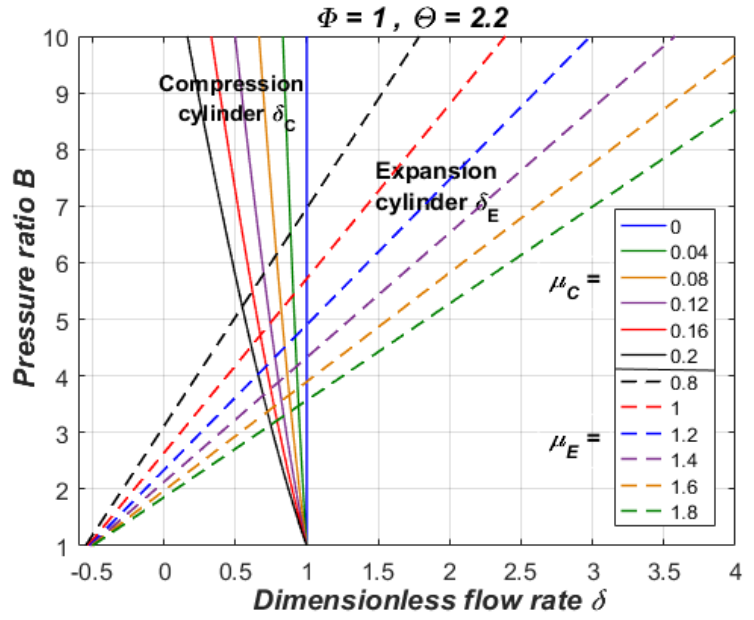

Figure 14. Operating points of the engine according to the command law 1 for $\Phi / \Theta=1 / 2.2$.

\subsubsection{Expansion cylinder}

Figure 13 shows the evolution of the dimensionless air flow rate $\delta_{E}$ of the expansion cylinder engine for law 1, as a function of the dead volume $\mu_{E}$ and the pressure ratio $B$ Eq. (7). The pressure ratio increases with the increase of the air flow rate and the decrease of the dead volume of the expansion machine. It is observed that the air flow is negative for very small values of the pressure ratio (less than 3 ), whatever the value of the dead volume in the range considered.

\subsubsection{Engine operating range}

By superimposing the curves of the dimensionless flow rates of the compression Eq. (1) and expansion cylinders for law 1 Eq. (7), the possible pairs of operating points $(\delta, B)$ can be obtained (Fig. 14). These operating points are located at the crossing between the curves $\delta_{E}$ and $\delta_{C}$. Each operating point corresponds to a well-defined engine whose characteristics are given by Eq. (12). It is observed in Figure 14 that this engine configuration exists only for pressure ratios greater than 3 , in the range of dead volumes considered. Unlike the Ericsson engine [12] for which it is possible that the curves $\delta_{E}$ and $\delta_{C}$ do not cross each other, there is always a solution for the intersection of the curves of the compression and expansion cylinder mass flow rate.

\subsection{Energy performance of the engine with expansion cylinder valves driven according to law 1}

Figure 15 presents the curves of the engine dimensionless net power depending on the pressure ratio $B$ for different values of the volume ratio $(\Phi=5,10$ and 20). These results are obtained for a dimensionless temperature $\Theta=2.2$ and a compressor relative dead space $\mu_{C}=0.1$ and for the values of $\mu_{E}$ from 0.01 to 10 . The first step of the calculation procedure consists in finding the value of the relative expansion unswept volume $\mu_{E}$ which satisfies the mass flow rate equality equation Eq. (11) for a given data set $(\Theta, \Phi, B)$. Figure 15 shows that the net power increases with the volume ratio $\Phi$. It is found that the net power reaches its maximum when the value of the pressure ratio $B$ is equal to about 3 and for a volume ratio $\Phi=$ 20 . Beyond this pressure ratio value, the engine net power decreases gradually. Figure 15 shows that the dimensionless net power of a hot air engine with expansion cylinder whose valves are actuated according to the law 1 is always lower than the theoretical conventional recuperative Joule cycle engine.

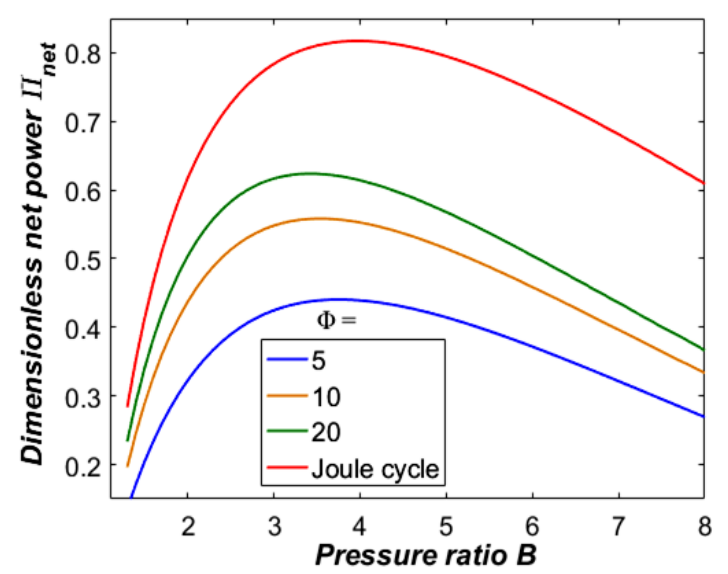

Figure 15. Dimensionless net power of the engine with expansion cylinder valves driven according to law 1 , for $\Theta=$ 2.2, $\mu_{E}=[0.01$ to 10$]$.

Figure 16 compares the efficiency obtained for the engine with valves actuated according to the law 1 with the performance of a conventional recuperative Joule cycle engine. The higher the volume ratio $\Phi$, the higher the thermal efficiency. Thus, it can be said that the thermal efficiency of the engine with valves driven according to the law 1 tends towards the thermal efficiency of a conventional expansion cylinder engine when the cubic capacity of the expansion volume becomes very large compared to that of the compression cylinder. Figure 16 shows that the thermal efficiency of the engine with valves actuated according to the law 1 is always lower than the one of a conventional recuperative Joule cycle engine. This result was expected since the engine with valves driven according to the law 1 introduces some irreversibilities during the exhaust process: when the exhaust valve opens, there is a sudden expansion of the working fluid through it. Despite this thermal efficiency difference, it is important to note that the engine with valves driven according to the law 1 remains a very attractive solution because of the simplicity of its distribution system that minimizes mechanical energy losses and makes it easier to design and to build than conventional Joule cycle Ericsson engine. For the engine with valves driven according to the law 1 with high volume ratios $\Phi$, it can be expected that the loss of thermal efficiency compared to a Joule cycle engine will be compensated by the reduction of the mechanical losses due to the actuation of the expansion valves.

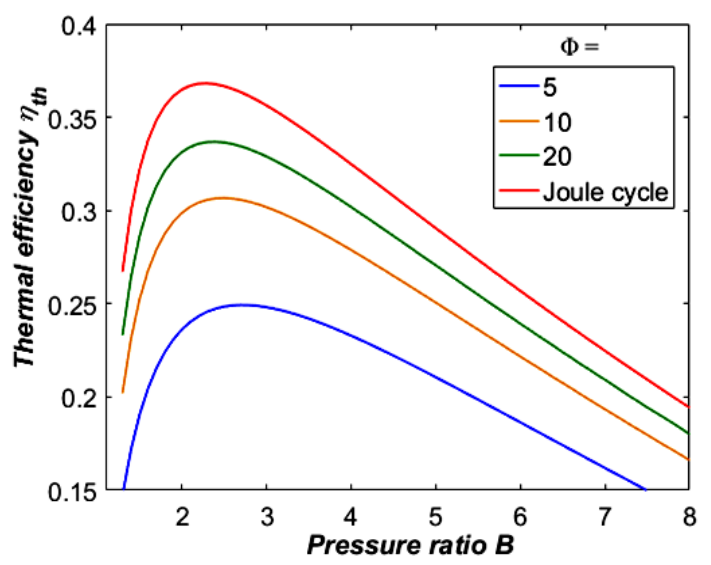

Figure 16. Thermal efficiency of the engine with expansion cylinder valves driven according to law 1 , for $\Theta=2.2, \mu_{E}=$ [0.01 to 10]. 
6.3. Energy performance of the engine with expansion cylinder valves driven according to law 2

The results presented in this section are a function of the pressure ratio $B$, the values of the volume ratio $(\Phi=5,10$ and 20 ) and the values of the closure delay of the inlet valve. Only two values of the delay of the inlet valve closing are presented ( $\alpha=0.1$ and $\alpha=0.2$ ). In this section we have not taken into account the case where $\alpha=0$ because this case corresponds to law 1 with the bash valve technology without any delay. The results of the engine with valves driven according to law 1 are already presented in the previous section through Figure 15 and Figure 16.

The first step of the calculation procedure consists in finding the value of the relative expansion unswept volume $\mu \mathrm{E}$ which satisfies the mass flow rate equality for a given data set $(\Theta, \Phi, \mathrm{B})$. These results are obtained for a dimensionless temperature $\Theta=2.2$ and a compressor relative dead space $\mu \mathrm{C}$ $=0.1$ and for the values of $\mu_{E}$ from 0.01 to 10 .

Figure 17 shows that the best values of dimensionless net power are obtained around the delay in closing the inlet valve $\alpha=0.1$ for a volume ratio $\Phi=10$ and a value of the pressure ratio $\mathrm{B}$ equal to approximately 3.2. For $\alpha=0.2$, the dimensionless net power decreases as the volume ratio increases. Figure 17 shows that the dimensionless net power of a hot air engine with expansion cylinder whose valves are actuated according to the law 2 is always lower than the theoretical conventional recuperative Joule cycle engine.

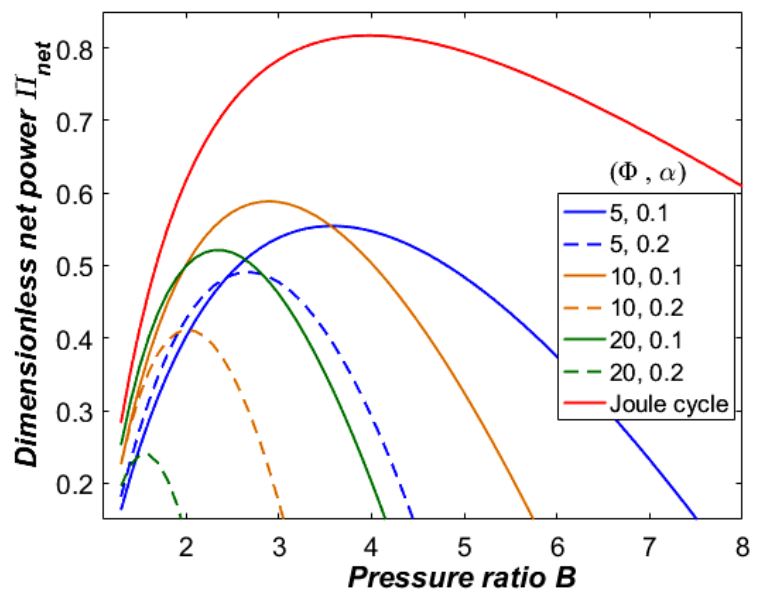

Figure 17. Dimensionless net power of the engine with valves driven according to law 2 for $\Theta=2.2, \mu_{E}=[0.01$ to 10].

Figure 18 shows that the best values of thermal efficiencies are obtained around the delay in closing the inlet valve $\alpha=0.1$ for a volume ratio $\Phi=10$. When the inlet valve closing delay increases to $\alpha=0.2$, the thermal efficiency deteriorates very strongly. It may therefore be thought that a slight delay in closing the inlet valve is relevant, insofar as it leads to the lower cubic capacity of expansion volume without unduly penalizing the thermal efficiency. The net power is very slightly reduced for $\alpha=0.1$ and $\Phi=10$ compared to the case where $\alpha=0$ and $\Phi=20$ of Figure 15 .

We can therefore notice that in the case of an engine with the inlet valve closing delay of 0.1 , we obtain a better ratio compromise between the cubic capacity of expansion volume and the cubic capacity of the compression volume which leads to good energy performance.

The evolution of the thermal efficiency of a theoretical conventional recovery Joule cycle is superimposed on Figure 18. It can be seen first of all that the thermal efficiency of a hot air engine with valves driven according to the law 2 is always lower than the one of a conventional Ericsson Joule cycle engine. This result was expected since, as in the case of law 1, in the engine with valves driven according to the law 2 some irreversibilities occur during the exhaust process: when the exhaust valve opens, there is a sudden expansion of the working fluid through it.

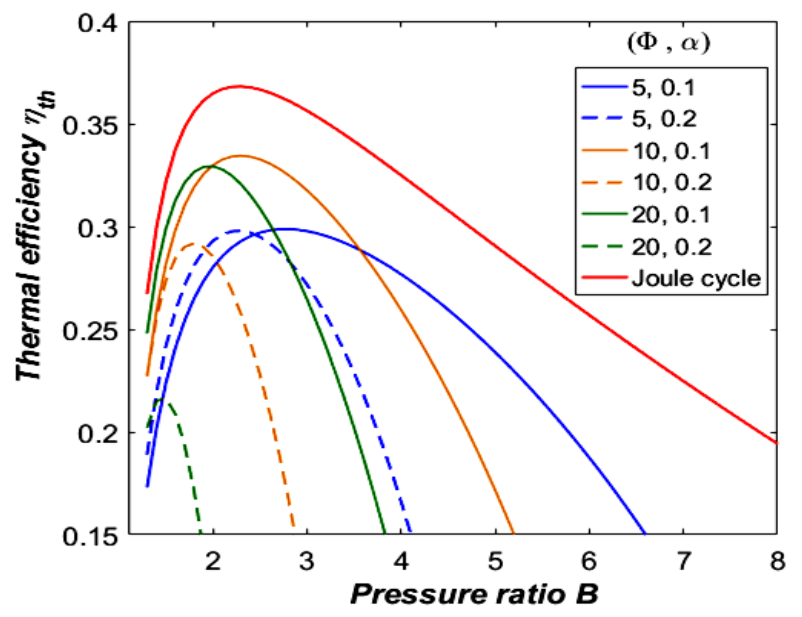

Figure 18. Thermal efficiency of the engine with valves driven according to law 2 for $\Theta=2.2, \mu_{E}=[0.01$ to 10].

\subsection{Energy performance of the engine with expansion cylinder valves driven according to law 3}

Figure 19 presents the engine dimensionless net power curves depending on the pressure ratio $\mathrm{B}$ for different values of the volume ratio $(\Phi=5,10$ and 20). These results are obtained for a dimensionless temperature $\Theta=2.2$ and a compressor relative dead space $\mu \mathrm{C}=0.1$ and for the values of $\mu_{E}$ from 0.237 to 4.45 . The first step of the calculation procedure consists in finding the value of the relative expansion unswept volume $\mu \mathrm{E}$ which satisfies the mass flow rate equality equation for a given data set $(\Theta, \Phi, \mathrm{B})($ Eq. 34). The value of the delay of inlet and outlet valve closing $\alpha$ given by Eq. (27) is superimposed on figure 19. It shows that the net power increases with the volume ratio $\Phi$. It is found that the net power reaches its maximum when the value of the pressure ratio $B$ is equal to about 3 and for a volume ratio $\Phi=20$. Beyond this pressure ratio value, the engine dimensionless net power decreases gradually. However, it can be noticed that when the volume ratio $\Phi$ decreases, the penalty on the net power is quite low. It can also be seen that the values of $\alpha$ that maximize the dimensionless net power are between 0.02 and 0.04 .

Figure 19 shows that the dimensionless net power of a hot air engine with expansion cylinder whose valves are actuated according to the law 3 is always lower than the theoretical conventional recuperative Joule cycle engine.

Figure 20 presents the thermal efficiency curves for an engine with expansion cylinder valves driven according to law 3 , depending on the pressure ratio $B$ for different values of the volume ratio ( $\Phi=5,10$ and 20 ). Again, the value of the delay of inlet and outlet valve closing $\alpha$ given by Eq. (27) is superimposed. The values of the pressure ratio $B$ which maximize the thermal efficiency (Figure 20) are lower than the ones which maximize the net power (Figure 19). It can be seen that the values of $\alpha$ that maximize the thermal efficiency are around 0.05 . It is found that the higher the volume ratio $\Phi$, the higher the thermal efficiency. Thus, it can be said that the thermal efficiency of a Joule cycle engine tends towards that of the conventional Joule cycle engine, when the volume ratio $\Phi$ increases. Figure 20 shows that for a pressure ratio of about 2.2 , the thermal efficiency reaches its maximum for each value 
of the volume ratio $\Phi$. The efficiency an engine with expansion cylinder valves driven according to law 3 , is always lower than that of a conventional recuperative Joule cycle engine. However, the penalty is much lower than in the case of laws 1 and 2 , and the decrease of the thermal efficiency with the volume ratio $\Phi$ is very low.

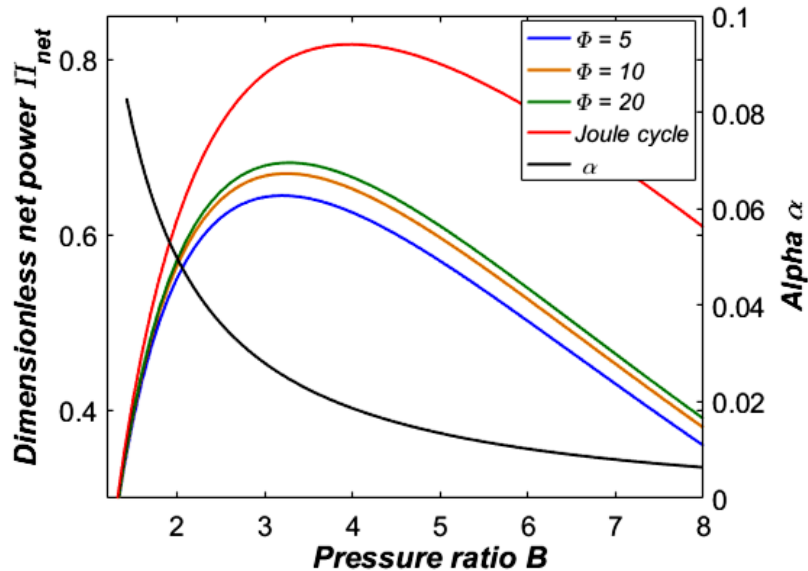

Figure 19. Dimensionless net power of the engine with valves driven according to law 3 for $\Theta=2.2, \mu_{E}=[0.237$ to 4.45].

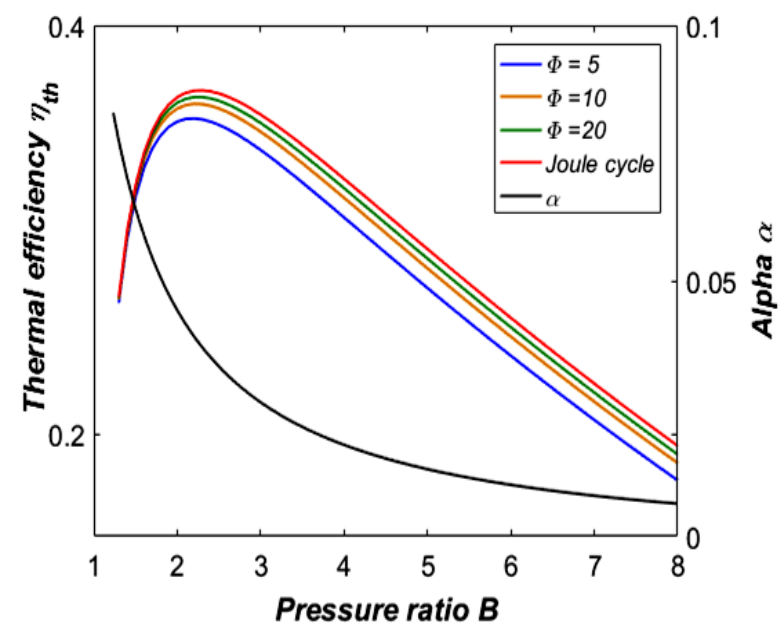

Figure 20. Thermal efficiency of the engine with valves driven according to law 3 for $\Theta=2.2, \mu_{E}=[0.237$ to 4.45].

\subsection{Comparison of the energetic performances of the three valves command laws of the hot air engine}

The comparison of the dimensionless net power obtained with the three valves command laws is presented for each value of the volume ratio considered previously, that is $\Phi=5$ (figure 21), $\Phi=10$ (figure 22), $\Phi=20$ (figure 23). It should be noted that for the case of the law 2 (bash valve technology with delay of inlet valve closing), the comparative study is done with an inlet valve closing delay $\alpha$ equal to 0.1 . This choice is justified with regard to the results obtained in section $\S 6.3$. It is reminded that in the case of law 3 , the inlet valve closing delay parameter $\alpha$ cannot be chosen freely as it is linked to the pressure ratio and the relative dead volume of the cylinder as shown in Eq. (27).

Whatever the volume ratio, law 3 always gives the best net power, with the maximum net power obtained for a pressure ratio of about 3 . Then law 2 gives better results than law 1 for $\Phi=5$ and $\Phi=10$, whereas law 1 is better than law 2 for $\Phi=$ 20 .

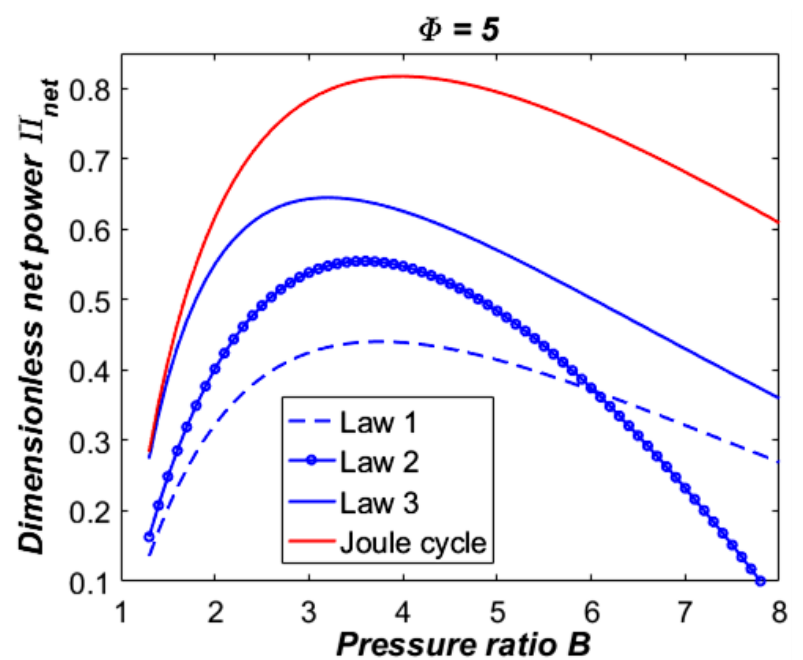

Figure 21. Comparison of the dimensionless net power for the 3 command laws $(\Phi=5)$.

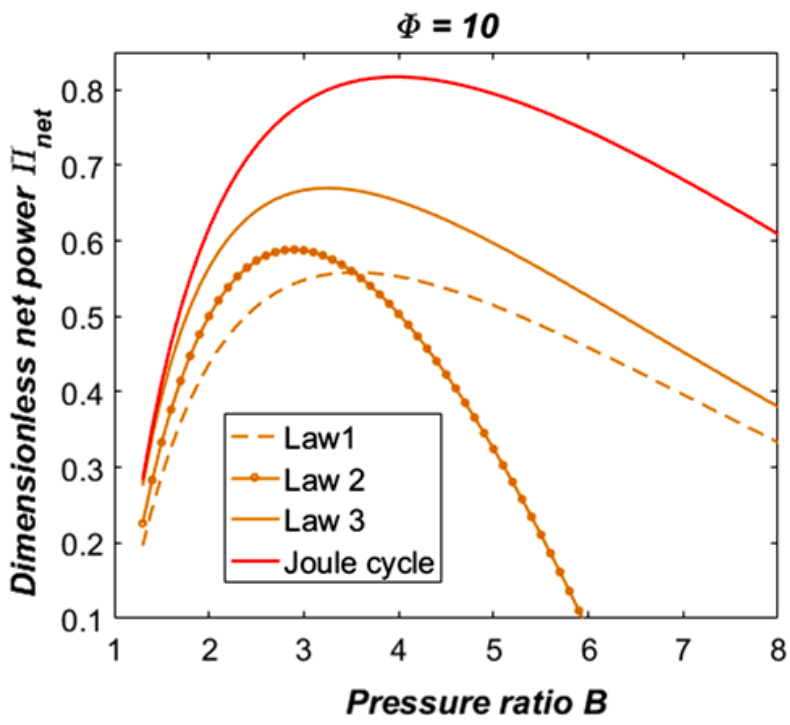

Figure 22. Comparison of the dimensionless net power for the 3 command laws $(\Phi=10)$.

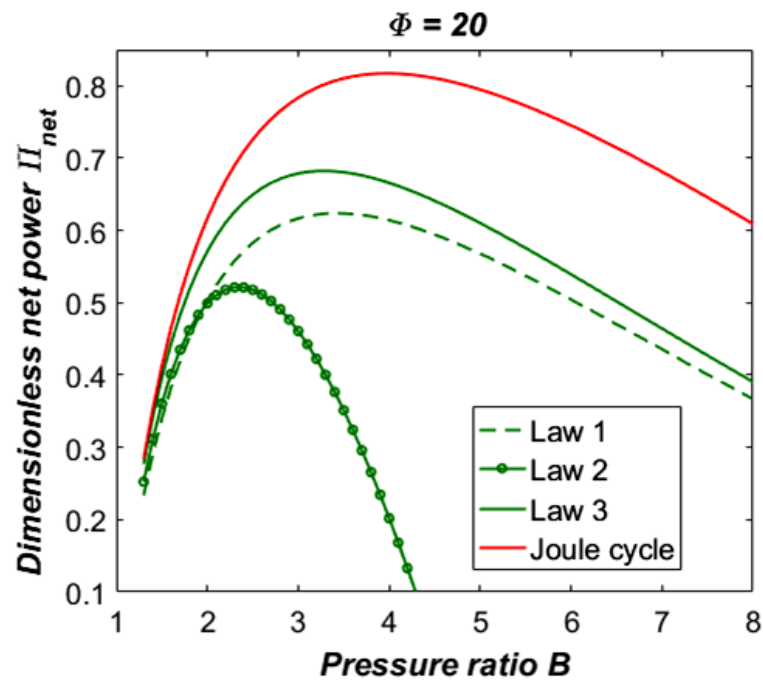

Figure 23. Comparison of the dimensionless net power for the 3 command laws $(\Phi=20)$.

In the same way, the three laws are compared for thermal efficiency in the figures 25 to 26. Again, whatever the volume ratio, law 3 always gives the best efficiency, with values very 
close to those of the Joule cycle, but with the maximum efficiency obtained for a pressure ratio of about 2.2, lower than the pressure ratio which maximizes the net power.

As in the case for net power, law 2 gives better results for the efficiency than law 1 for $\Phi=5$ and $\Phi=10$, whereas law 1 is better than law 2 for $\Phi=20$.

For the engine equipped with the bash valve technology without delay (law 1), it is found that the thermal efficiency increases with the volume ratio. Thus we observe the maximum efficiency $\eta$ th $=0.3369$ for a volume ratio $\Phi=20$. For the engine equipped with the bash valve technology with an inlet valve closing delay $\alpha=0.1$ (law 2), it can be seen that the thermal efficiency reaches a maximum efficiency of $n$th $=$ 0.3345 for a volume ratio equal to 10 , whereas the corresponding value for law 3 is $\eta_{\text {th }}=0.3616$ with the same volume ratio.

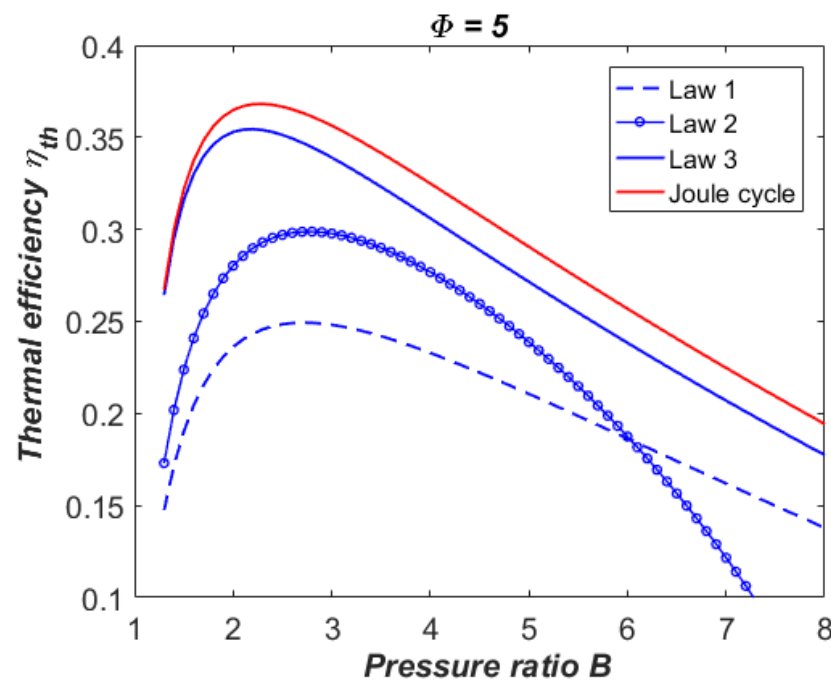

Figure 24- Comparison of the thermal efficiency for the 3 command laws $(\Phi=5)$

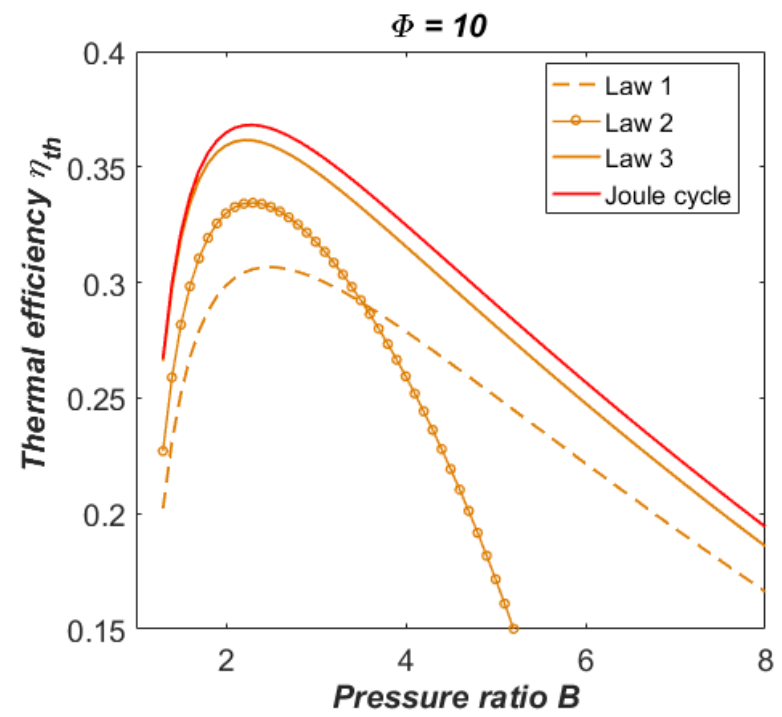

Figure 25. Comparison of the thermal efficiency for the 3 command laws $(\Phi=10)$.

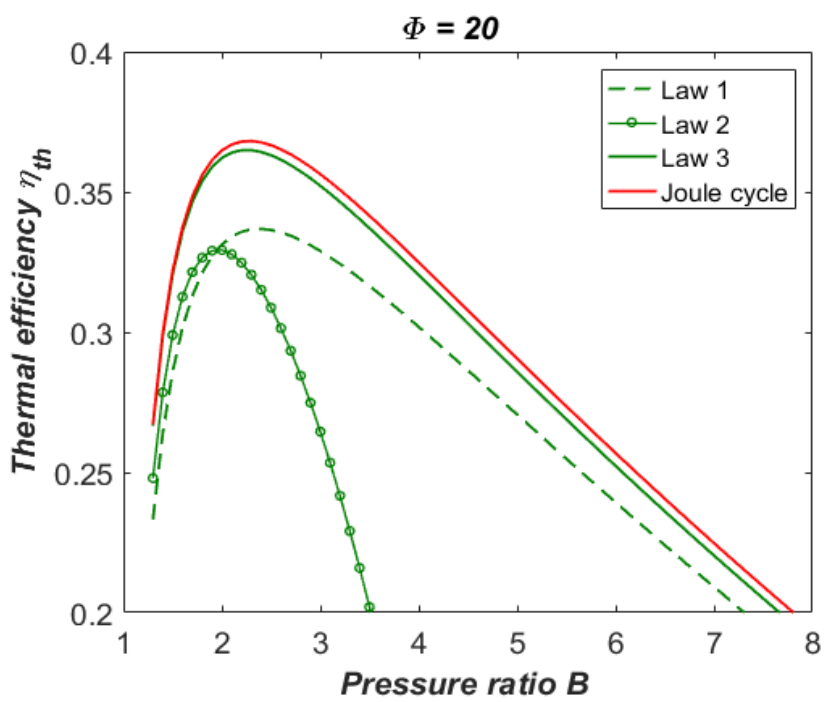

Figure 26. Comparison of the thermal efficiency for the 3 command laws $(\Phi=20)$.

In view of the results obtained, it appears that the designer has to make a choice between an engine equipped with the bash valve technology, which is of unquestionable simplicity from the technological point of view, but on the other hand only leads to good energy performance for high volume ratios; and an expansion cylinder equipped with valves actuated with the same delay of closing, which offers improved energy performance for a distribution system which can be simple if the engine is built with two expansion cylinders in phase opposition. Law 2 can represent an interesting compromise if one accepts more important cubic capacity of expansion volume $(\Phi=10)$.

\section{CONCLUSION}

The performance of a specific hot air engine is studied. In this engine, the compression cylinder is equipped with usual automatic valves, while the expansion cylinder uses actuated valves. Three different valves command laws of the hot air engine have been studied and their influences on the design and energy performance of the system are presented. This study highlights the advantage of an engine equipped with the bash valve technology, whose technological simplicity is indisputable, at the expense of very large cylinder volumes for good energy performance.

\section{ACKNOWLEGEMENT}

The authors are thankful for Michel GUERY who drew their attention to the steam engine inlet valve mechanism.

\section{NOMENCLATURE}

$c_{p}=$ specific heat capacity at constant pressure, $\left(\mathrm{J} . \mathrm{kg}^{-1} \cdot \mathrm{K}^{-1}\right)$

$c_{v}=$ specific heat capacity at constant volume, $\left(\mathrm{J} \mathrm{kg}^{-1} \cdot \mathrm{K}^{-1}\right)$

$k=(\gamma-1) / \gamma$

$m=$ mass of the working fluid, $(\mathrm{kg})$

$\dot{m}=$ mass flow rate of the working fluid, $\left(\mathrm{kg} . \mathrm{s}^{-1}\right)$

$n=$ rotational speed,$\left(\mathrm{s}^{-1}\right)$

$p=$ pressure, $(\mathrm{Pa})$

$Q=$ heat, $(\mathrm{J})$

$\dot{Q}=$ thermal power, $(\mathrm{W})$

$r=$ perfect gas constant, $\left(\mathrm{J} \mathrm{kg}^{-1} \cdot \mathrm{K}^{-1}\right)$

$T=$ temperature, $(\mathrm{K})$

$V=$ volume, $\left(\mathrm{m}^{3}\right)$

$w=$ work per unit mass of the working fluid, $\left(\mathrm{J}^{\mathrm{kg}} \mathrm{kg}^{-1}\right)$

$W=$ work, $(\mathrm{J})$ 
$\dot{W}=$ mechanical power, $(\mathrm{W})$

Greek symbols

$\beta=$ dimensionless pressure

$B=$ cycle pressure ratio

$\gamma=\mathrm{cp} / \mathrm{cv}$

$\delta=$ dimensionless mass or mass flow rate

$\varepsilon=$ effectiveness of the heat recovery exchanger

$\eta_{t h}=$ thermal efficiency

$\theta=$ dimensionless temperature

$\Theta=$ cycle temperature ratio

$\mu=$ relative dead volume

$\Pi=$ dimensionless work or power

$\varphi=$ dimensionless volume

$\Phi=V_{E} / V_{C}$

\section{Subscripts}

$c r=$ fluid state between $C$ and $R$

$C=$ compression cylinder

$E=$ expansion cylinder

$e r=$ fluid state between $E$ and $R$

$h=$ fluid state at the exit of $H$

$H=$ heater

$k=$ fluid state at the inlet of $C$ (ambient state)

$R=$ heat recovery exchanger (recuperator)

$r h=$ fluid state between $R$ and $H$

$r k=$ fluid state between $R$ and $K$ (exhaust)

\section{REFERENCES}

[1] International Energy Agency, 2014 Annual Report, https://www.iea.org/publications/.../2014_IEA_Annual Report.pdf

[2] T. H. Finkelstein, A. J. Organ, Air engines. London: Professional Engineering Publishing Ltd, 2001.

[3] P. Stouffs, „Hot Air Engines,“ Journal of Applied Fluid Mechanics, 4, 1-8, 2011.

[4] M. Creyx, E. Delacourt, C. Morin, B. Desmet, P. Peultier, "Energetic optimization of the performances of a hot air engine for micro-CHP systems working with a Joule or an Ericsson cycle," Energy, 49, 229-239, 2013.

[5] S. Bonnet, M. Alaphilippe, P. Stouffs, "Energy, exergy and cost analysis of a micro-cogeneration system based on an Ericsson engine," Int J Therm Sci, 44(12), 1161-8, 2005.

[6] Touré A. (2010) Etude théorique et expérimentale d'un moteur Ericsson destiné à la microcogénération $(\mathrm{PhD}$ thesis), Pau: UPPA.

[7] M. Alaphilippe, S. Bonnet, P. Stouffs, "Low power thermodynamic solar energy conversion: coupling of a parabolic trough concentrator and an Ericsson engine," Int. J. of Thermodynamics, 10, 37-45, 2007.

[8] W. G. Le Roux, T. Bello-Ochende, J. P. Meyer, “A review on the thermodynamic optimisation and modeling of the solar thermal Brayton cycle," Renewable and sustainable energy reviews, 28, 677-690, 2013.

[9] A. Touré, P. Stouffs, "Modeling of the Ericsson engine," Energy, 76(1), 445-452, 2014.

[10] R. W. Moss, A. P. Roskilly, S. K. Nanda, "Reciprocating Joule-cycle engine for domestic CHP systems, “ Applied Energy, 80, 169-185, 2005.
[11] J. Wojewoda, Z. Kazimierski, "Numerical model and investigations of the externally heated valve Joule engine, “Energy, 35, 2099-2108, 2010.

[12] E. Kussul, O. Makeyev, T. Baidyk, O. Olvera, "Design of Ericsson Heat Engine with Micro Channel Recuperator, Renewable Energy, 8, 613642, 2012.

[13] M. A. Bell, T. Partridge, "Thermodynamic design of a reciprocating Joule cycle engine," Proc Instn Mech Engrs Part A J Power \& Energy, 217, 239-246, 2003.

[14] R. Ibsaine, P. H. Sène, P. Stouffs, "Moteurs Volumétriques Alternatifs à Apport de Chaleur Externe : Comparaison entre les Machines à Cycle de Joule et les Machines à Cycle de Rankine," Actes du Colloque COFRET. Sofia: Université technique; 2012.

[15] R. Ibsaine, P. Stouffs, "Modeling of a humid air reciprocating regenerative Joule cycle Ericsson engine," 15th International Stirling Engine Conference (ISEC). Roma: Int. Stirling Engine Committee; 2012.

[16] F. Lontsi, O. Hamandjoda, K. Fozao, P. Stouffs, J. Nganhou, "Dynamic simulation of a small modified Joule cycle reciprocating Ericsson engine for microcogeneration systems, “ Energy, 63, 309-316, 2013.

[17] M. Creyx, E. Delacourt, C. Morin, B. Desmet, "Dynamic modelling of the expansion cylinder of an open Joule cycle Ericsson engine: A bond graph approach,“ Energy, 102, 31-43, 2016.

[18] M. Creyx, E. Delacourt, C. Morin, S. Lalot, B. Desmet, "Energetic and Exergetic Analysis of a Heat Exchanger Integrated in a Solid Biomass-Fuelled Micro-CHP System with an Ericsson Engine," Entropy, 18, 154, 2016.

[19] A. Fula Rojas, F. Sierra Vargas, P. Stouffs, "Étude paramétrique globale de l'influence des transferts thermiques au travers des parois des cylindres d'un moteur Ericsson," Actes du Colloque CIFEM ART-10-52, Ouagadougou: 2ie, 2012.

[20] A. Fula, P. Stouffs, F. Sierra, "In-Cylinder Heat Transfer in an Ericsson Engine Prototype," Renewable Energy and Power Quality Journal, 11, 594, 2013.

[21] Bash valve, https://en.wikipedia.org/wiki/Bash_valve , [Accessed: 28-Sept-2018].

[22] Harold V.Sturtevant, Steam engine inlet valve mechanism, Unites States Patent Office 3.397.619, patented August 20, 1968.

[23] Stumpf, The una-flow steam-engine, 1922. [Online]. https://archive.org/stream/cu31924015551702\#page/n3/ mode/1up. [Accessed: 28-Sept-2018].

[24] Marcin Jakubowski, The Modern steam engine, OSE project.https://sites.google.com/site/phase3project/projec ts/steam-engine/engine-designs/ose-arrow-head-engine. [Accessed: 28-Sept-2018].

[25] P. Bannister, "The ANU Solar Thermal Steam Engine: Performance Analysis," International Journal of Energy Research, 22, 303-316, 1998.

[26] Da Silva B. (2018). The development, construction and testing of a piston expander for small-scale solar thermal power plants (Master of thesis in Engineering), Stellenbosch University. 